\title{
Recurrence of the D409H mutation in Spanish Gaucher disease patients: description of a new homozygous patient and haplotype analysis
}

\author{
Amparo Chabás, Laura Gort, Magda Montfort, Francesc Castelló, \\ M Carmen Domínguez, Daniel Grinberg, Lluïsa Vilageliu
}

Institut de Bioquímica Clínica, Mejía

Lequerica s/n, Edificio Helios III, Planta

Baixa, E-08028

Barcelona, Spain

A Chabás

L Gort

Departament de Genètica, Facultat de Biologia, Universitat de Barcelona, Av

Diagonal 645, E-08071

Barcelona, Spain

$M$ Montfort

D Grinberg

L Vilageliu

\section{Hospital}

Materno-Infantil Vall

d'Hebron, Servei de

Pediatria, Pg Vall

d'Hebron s/n, E-08035

Barcelona, Spain

F Castelló

Hospital Vall

d'Hebron, Centre d'Investigacions en

Bioquímica i Biologia

Molecular, Pg Vall

d'Hebron s/n, E-08035

Barcelona, Spain

M C Domínguez

Correspondence to: Dr Chabás.

Received 23 October 1997 Revised version accepted for publication 6 February 1998

\begin{abstract}
Gaucher disease results, in most patients, from mutations in the gene encoding glucocerebrosidase. Mutation D409H is the third most frequent in Spanish patients, accounting for $5.7 \%$ of all mutated alleles. This allele is associated mainly with the neurological forms of the disease. Recently, homozygosity for the D409H mutation has been associated with a particular phenotype, including specific cardiovascular symptoms. Here we report a second Spanish patient bearing the D409H/ D409H genotype with a very early manifestation of the disease. The patient started enzyme replacement therapy at 3 months of age. A common origin for the Spanish D409H alleles was ruled out by haplotype analysis using an internal polymorphism of the glucocerebrosidase gene and two external microsatellite markers. (F Med Genet 1998;35:775-777)
\end{abstract}

Keywords: Gaucher disease; mutation D409H; haplotype analysis; enzyme replacement therapy

Gaucher disease (GD) is a clinically heterogeneous sphingolipidosis caused mainly by mutations in the gene encoding lysosomal glucocerebrosidase (GBA). Mutations in the GBA gene may be classified as lethal, severe, or mild on the basis of the severity of their phenotypic effect. ${ }^{1}$ A genotype-phenotype correlation has been established for the most common mutations, such as N370S $(1226 \mathrm{~A} \rightarrow \mathrm{G})$ with a nonneuronopathic phenotype or L444P $(1448 \mathrm{~T} \rightarrow \mathrm{C})$ with a severe phenotype. ${ }^{2} \mathrm{Re}-$ cently, homozygosity for the D409H mutation $(1342 \mathrm{G} \rightarrow \mathrm{C}$ ) has been associated with a unique form of type 3 Gaucher disease in patients with origins as diverse as Spanish, ${ }^{3}$ Arab, ${ }^{4}$ British/German, ${ }^{5}$ and Japanese. ${ }^{6}$ They all had oculomotor apraxia and a devastating valvular heart disease. Common manifestations of GD were not evident and minimal visceral organomegaly, or even absence, was reported in most patients. Corneal opacity was also mentioned in the Spanish, Arab, and Japanese patients while some other features, such as sensorineural deafness, hernia, and deformed toes, found in patients with mucopolysaccharidosis or glycoprotein disorders, were only observed in the Japanese cascs.

In total, only six unrelated patients with the confirmed D409H/D409H genotype have been described. ${ }^{3-6}$ We now report a second
Spanish patient homozygous for the $\mathrm{D} 409 \mathrm{H}$ mutation with a very early manifestation of GD, presenting exclusively with massive hepatosplenomegaly. $\mathrm{D} 409 \mathrm{H}$ is the third most common mutation in the Spanish GD population ${ }^{7}$ and we have identified six unrelated families bearing this mutation. Although a common origin for all $\mathrm{D} 409 \mathrm{H}$ alleles was ruled out because of the association with both the " + " and "-" internal haplotypes, ${ }^{58}$ we carried out haplotype analyses using highly informative flanking markers ${ }^{9}$ to evaluate the degree of recurrence of this mutation.

\section{Case report}

The patient, now 13 months old, was admitted to hospital at the age of 6 days because of respiratory distress. Hepatosplenomegaly was then detected (spleen 3-3.5 cm and liver 1.5-2 $\mathrm{cm}$ below the costal margin). $X$ rays of the chest, bone metaphyses, and skull were normal. Multiple haemorrhages in the retina were observed. The patient was readmitted at the age of 1.5 months because of massive hepatosplenomegaly (spleen $7 \mathrm{~cm}$ and liver $5 \mathrm{~cm}$ below the costal margin) with abdominal colic pains. Serology was negative. Blood counts (haemoglobin, haematocrit, red blood cells) were just below normal values. Chitotriosidase activity was raised $(1467 \mathrm{nmol} / \mathrm{h} \times \mathrm{ml}$, controls 31.6 (SD17.2)). The blood clotting parameters were normal as well as a bone marrow aspirate. Neurological evaluation (electroencephalography, brain auditory evoked response, and CT of the brain) was normal.

Acid $\beta$-glucosidase activity was decreased to $23 \%$ (leucocytes) and $3.8 \%$ (fibroblasts) of controls. Urine samples were not available.

The patient started enzyme replacement therapy with Alglucerase (Ceredase $(B)$ at 3 months of age. At the age of 13 months neurological examination and ocular motility were normal. Echocardiography was also normal. Hepatomegaly was drastically reduced and the spleen was $3 \mathrm{~cm}$ below the costal margin.

\section{Mutation analysis}

Genomic DNA amplification by PCR and SSCP analyses were performed as previously described. ${ }^{10}$ The presence of an altered pattern similar to that found in our previous case ${ }^{3}$ and subsequent confirmation by sequencing showed that the patient is homozygous for the $\mathrm{D} 409 \mathrm{H}$ mutation. Both parents are heterozygous for this mutation. The parents are not consanguineous and are from a different region 
of Spain from the previously reported family. A prenatal diagnosis was recently requested by this family. Deficiency of acid $\beta$-glucosidase activity and homozygosity for mutation $\mathrm{D} 409 \mathrm{H}$ suggested an affected fetus. The pregnancy was terminated and the diagnosis of Gaucher disease was confirmed in the fetal tissue.

\section{Haplotype analysis on chromosomes bearing the D409H mutation}

Haplotype analysis was carried out on eight alleles bearing $\mathrm{D} 409 \mathrm{H}$, including the case reported here (patient 1 ), a previously undescribed patient (patient 6), and four other patients reported elsewhere ${ }^{38}$ (table 1). The $6144 \mathrm{~A} \rightarrow \mathrm{G}$ polymorphism in intron 9 of the GBA gene was analysed by $H$ haI digestion of a PCR amplified product. Gene specific primers (sense: nt 5904-5923, antisense: 6655-6690, sequence according to Horowitz et al, ${ }^{11}$ EMBL GenBank accession number J03059) were used to amplify a $787 \mathrm{bp}$ fragment. ${ }^{12}$ The alleles were designated "+" (HhaI site present) or "-" (HhaI site absent), following Beutler et al. ${ }^{13}$

The association of $\mathrm{D} 409 \mathrm{H}$ with either the "+" or the "-" variants of the $6144 \mathrm{~A} \rightarrow \mathrm{G}$ polymorphism was studied. Phase was established either by genotyping the parents or by cloning a DNA fragment containing both the mutation and the polymorphic site. Results of the analysis of the HhaI polymorphism for some of these patients have been previously presented. ${ }^{8}$ Only one of the alleles was associated with the "+" allele while seven were associated with the "-" allele of the internal polymorphism (table 1).

Two external microsatellite markers D1S2140 and D1S2624, known to be at 0 and $1.6 \mathrm{cM}$ respectively from the GBA gene ${ }^{9}$ were used to genotype the eight $\mathrm{D} 409 \mathrm{H}$ chromosomes. These markers belong to the MapPairs set (Research Genetics) and were analysed according to the manufacturer's recommendations. Marker D1S2140 has seven alleles with the following sizes: allele 1,232 bp; 2,$244 ; 3$, $248 ; 4,252 ; 5,254 ; 6,256$; and 7, 260. Marker D1S2624 has five alleles: allele 1, 209 bp; 2, $205 ; 3,211 ; 4,203$; and 5, 207. The eight D409H chromosomes presented six different haplotypes (table 1). Only patients 1 and 5 share the same one. In addition, patient 2 is homozygous for all three loci. Linkage disequilibrium between $\mathrm{D} 409 \mathrm{H}$ and each of the markers was not significant (data not shown).

Table 1 Haplotype analysis for the $6144 A \rightarrow G$ polymorphism and markers D1S2140 and D1S2624 in patients bearing the D409H mutation

\begin{tabular}{lllll}
\hline Patients & GBA mutations & $6144 A \rightarrow G$ & $D 1 S 2140$ & D1S2624 \\
\hline 1 (case report) & D409H & - & 4 & 1 \\
& D409H & - & 1 & 4 \\
2 (type 3)† & D409H & - & 4 & 4 \\
& D409H & - & 4 & 4 \\
3 (type 1) & D409H & - & 7 & 1 \\
4 (type 2) $\ddagger$ & E326K & + & 4 & 1 \\
& D409H & + & 4 & 3 \\
5 (type 3) $\ddagger$ & R120W & + & 6 & 3 \\
& D409H & - & 1 & 4 \\
6 (type 1) $^{\star}$ & L444P & + & 3 & 4 \\
& D409H & - & 1 & 2 \\
& G377S & - & 4 & 1
\end{tabular}

`This paper. †Reference 3. $¥$ Reference 8. Haplotypes for D409H chromosomes are shown in bold.

\section{Discussion}

A very limited number of patients homozygous for mutation $\mathrm{D} 409 \mathrm{H}$ have been reported so far. The patient described here was diagnosed at 1.5 months of age because of massive hepatosplenomegaly. Despite the early presentation of the disease, the absence of neurological signs ruled out the acute, infantile form of GD. Characteristic findings in patients bearing the D409H/D409H genotype, such as ophthalmoplegia and cardiovascular abnormalities, were not noticed in our patient, probably because of the young age. Ophthalmoplegia had been noticed in early childhood in some patients homozygous for mutation $\mathrm{D} 409 \mathrm{H}^{4} 6$ while in others gaze palsy started at 15-16 years of age. ${ }^{3}$ In these patients, cardiac involvement consisting of valvular calcifications was also apparent in late childhood. ${ }^{34}$

The patients of Japanese origin ${ }^{6}$ provide the most atypical clinical picture as they present a combination of clinical signs which appear just as isolated features in some patients of other origins. The massive visceromegaly of the patient reported here, absent in the Japanese patients and moderate in other cases, increases the range of heterogeneity in patients with the D409H/D409H genotype.

To date, there have been no published data on a patient with this genotype receiving enzyme replacement therapy. The case reported, now at the age of 13 months and after 10 months of treatment, shows no signs of cardiac involvement. As expected, the splenomegaly and hepatomegaly have been reduced and the patient shows a normal haemogram. If the patient does not present cardiac disease later in life, as did all the other D409H/D409H patients previously reported, it will be difficult to assess if this is because of the early treatment or phenotypic heterogeneity. It should be noted that reversible cardiomyopathy with enzyme replacement therapy has recently been reported in a 5 year old patient with type $1 \mathrm{GD}^{14}$

For haplotype analysis, five other patients were analysed, including one previously undescribed (patient 6). This patient is a 47 year old type 1 woman who bears genotype D409H/ G377S $(1246 \mathrm{G} \rightarrow \mathrm{A})$. This is the first description of mutation G377S in the Spanish population. Interestingly, it is the third most prevalent mutation in Portugal. ${ }^{15}$

In order to determine whether mutation $\mathrm{D} 409 \mathrm{H}$ was present by descent from a single origin or the result of independent mutational events, we carried out haplotype analysis using one of the internal polymorphisms of the GBA gene and two external but very close markers on the eight alleles found in the Spanish population. The analysis of the internal polymorphism showed that only one $\mathrm{D} 409 \mathrm{H}$ allele was associated with the "+" allele while the rest were associated with the "-"allele, as previously determined ${ }^{8}$ with some of the samples. This ruled out a single origin for the Spanish D409H mutation, but a founder effect for the seven chromosomes bearing the "-" allele of the HhaI internal polymorphism could not be excluded. However, the analysis of the highly polymorphic markers D1S2140 and D1S2624, 
known to be at 0 and $1.6 \mathrm{cM}$ respectively from the GBA gene, ${ }^{9}$ showed that the $\mathrm{D} 409 \mathrm{H}$ mutations are associated with different haplotypes. Only haplotype D409H-1-4 appeared in two different patients (table 1). The two chromosomes of patient 2 showed the same haplotype, suggesting consanguinity, although the family was not aware of this. The lack of association between $\mathrm{D} 409 \mathrm{H}$ and the markers indicate that $\mathrm{D} 409 \mathrm{H}$ is a recurrent mutation. As the site of the mutation is not a $\mathrm{CpG}$ dinucleotide, known to be a mutational hot spot, and as it is present in the pseudogene, gene conversion events could explain this recurrence.

The authors are grateful to Dr B Cormand, S Guidi, N Garcia $\mathrm{J}$ Jarque, and E Sellés for excellent technical assistance and discussion, and to R Rycroft for revising the English. This work was supported by CICYT (SAF 97-0074).

1 Beutler E, Demina A, Gelbart T. Glucocerebrosidase mutations in Gaucher disease. Mol Med 1994;1:82-92.

2 Horowitz M, Zimran A. Genotype-phenotype correlation in Gaucher disease. In: Humphries SE, Malcolm S, eds. From genotype to phenotype. Oxford: BIOS Scientific Publishers, 1994:67-81.

3 Chabás A, Cormand B, Grinberg D, et al. Unusual expression of Gaucher's disease: cardiovascular calcifications in three sibs homozygous for the $\mathrm{D} 409 \mathrm{H}$ mutation. $\mathcal{F}$ Med Genet 1995;32:740-2.

4 Abrahamov A, Elstein D, Gross-Tsur V, et al Gaucher's disease variant characterised by progressive calcification of heart valves and unique genotype. Lancet 1995;346: 1000-3

5 Beutler E, Kattamis C, Sipe J, Lipson M. 1342C mutation in Gaucher's disease. Lancet 1995;346:1637.

6 Uyama $\mathrm{E}$, Uchino $M$, Ida $\mathrm{H}$, Eto $\mathrm{Y}$, Owada $M$ $\mathrm{D} 409 \mathrm{H} / \mathrm{D} 409 \mathrm{H}$ genotype in Gaucher-like disease. $7 \mathrm{Med}$ Genet 1997;34:175.

7 Cormand B, Vilageliu L, Burguera JM, et al. Gaucher Cormand B, Vilageliu L, Burguera JM, et al. Gaucher
disease in Spanish patients: analysis of eight mutations. disease in Spanish patients

8 Chabás A, Cormand B, Balcells S, et al. Neuronopathic and non-neuronopathic presentation of Gaucher disease in patients with the third most common mutation (D409H) in Spain. F Inherit Metab Dis 1996;19:798-800.

9 Cormand B, Montfort M, Chabás A, Vilageliu L, Grinberg D. Genetic fine localization of the beta glucocerebrosidase (GBA) and prosaposin (PSAP) genes: implications for Gaucher disease. Hum Genet 1997;100:75-9.

10 Cormand B, Grinberg D, Gort L, et al. Two new mild homozygous mutations in Gaucher disease patients: clinical signs and biochemical analyses. Am $\mathcal{F}$ Med Genet 997; $70: 437-43$

11 Horowitz M, Wilder S, Horowitz Z, Reiner O, Gelbart T, Beutler E. The human glucocerebrosidase gene and pseudogene: structure and evolution. Genomics 1989;4:8796.

12 Sidransky E, Tsuji S, Martin BM, Stubblefield B, Ginns EI. DNA mutation analysis of Gaucher patients. $\mathrm{Am} \mathcal{F} \mathrm{Med}$ Genet 1992;42:331-6.

13 Beutler E, West C, Gelbart T. Polymorphisms in the human glucocerebrosidase gene. Genomics 1992;12:795-800.

14 Spada M, Chiappa E, Sacchetti C, Ciriotti G, Ponzone A Reversible cardiomyopathy with enzyme replacement therapy in Gaucher's disease type 1. F Inherit Metab Dis 1997;20(suppl.1):76.

15 Amaral O, Pinto E, Fortuna M, Lacerda L, Miranda M Type 1 Gaucher disease: identification of N396T and prevalence of glucocerebrosidase mutations in the Portuguese. Hum Mutat 1996;8:280-1. 